\title{
Yargıya yansıyan avasküler nekroz vakalarının tıbbi ve hukuki değerlendirilmesi
}

\section{Medical and legal evaluation of avascular necrosis cases reflected in the judiciary}

\author{
Serdar Şirazi ${ }^{1}$, Irfan Esenkaya ${ }^{2}$ \\ ${ }^{1}$ Ortopedi ve Travmatoloji Uzmanı, Hukukçu, Arabulucu; Özel Avcılar Anadolu Hastanesi; Şahin Avukatlık Bürosu, İstanbul \\ ²Emekli Öğretim Üyesi, Ortopedi ve Travmatoloji Uzmanı, SANTE Tıp Merkezi, İstanbul; Tıp Hukuku Yüksek Lisansı, MA
}

\begin{abstract}
Avasküler nekrozun (osteonekrozun) etiyolojisinde yaygın olarak travma olabilmekle birlikte diğer nedenler içerisinde steroid kullanma öyküsü, basınç farkına bağlı emboli gelişmesi veya idiyopatik avasküler nekrozlar sayılabilmektedir. Hukuki açıdan bu durum iş kazası, meslek hastalığı veya tedavi komplikasyonları şeklinde karşımıza çıkabilmekte, bazı durumlarda da tıbbi uygulama hatası sonucu gelişebilmektedir. Makalemizde yüksek yargıya yansıyan avasküler nekroz davalarının birkaçı hukuki ve tıbbi açıdan incelenerek ortopedi ve travmatoloji uzmanlarına farklı bir bakış açısı sağlanması hedeflenmektedir.
\end{abstract}

Anahtar sözcülkler: avasküler nekroz; osteonekroz; komplikasyon; malpraktis; sağlık hukuku; tıp hukuku

\begin{abstract}
Although trauma may be common in the etiology of osteonecrosis, history of steroid use, embolus development due to differences in pressure or idiopathic avascular necroses can be other causes. In legal terms, this situation may be encountered in the form of work accidents, occupational diseases or treatment complications, and in some cases, may develop as a result of medical malpractice. Our article aims to provide orthopedics and traumatology specialists a different perspective by examining some of the avascular necrosis phenomena carried to high judiciary from a legal and medical perspective.
\end{abstract}

Key words: avascular necrosis; osteonecrosis; complication; malpractice; health law; medical law
O steonekroz (ON) ya da yaygın kullanılan ismi ile avasküler nekroz (AVN) ortopedi ve travmatoloji pratiğinin önemli ve bir o kadar da sıkıntılı sürece sahip problemi olarak günlük pratiklerde karşılaşılabilen hastalıklardandır. Hastalar için tanı, tedavi ve klinik süreci zor olmakla birlikte ortopedi ve travmatoloji uzmanları için de tedavi sonucu her zaman tatmin edici olmayabilmektedir.

Avasküler nekroz etiyolojisinde yaygın olarak travma olabilmekle birlikte diğer nedenler içerisinde steroid kullanma öyküsü, basınç farkına bağlı emboli gelişmesi veya idiyopatik avasküler nekrozlar sayılabilmektedir. Hukuki açıdan bu durum iş kazası, meslek hastalığı veya tedavi komplikasyonları şeklinde karşımıza çıkabilmekte, bazı durumlarda da tıbbi uygulama hatası sonucu olarak da gelişebilmektedir.

Örneğin uçak kabin çalışanlarında veya profesyonel dalgıçlık yapanlarda gelişen avasküler nekroz hastalığı meslek hastalığı olarak kabul edilebilmekle birlikte, iş yerinde düşme sonucu femur boyun kırığı gelişmesi durumunda ortaya çıkan avasküler nekroz iş kazası statüsünde olabilmektedir.

\section{HUKUKSAL DEĞERLENDIRME}

Makalemizde yüksek yargıya yansıyan avasküler nekroz davalarının birkaçı hukuki ve tıbbi açıdan incelenerek ortopedi ve travmatoloji uzmanlarına farklı bir bakış açısı sağlanması hedeflenmektedir.

Yüksek mahkemelere yansıyan avasküler nekroz davaları incelendiğinde idarenin sorumluluğu açısından idare hukuku bünyesinde değerlendirilen davalar olmakla birlikte hekimin tıbbi uygulama hatası sonucu geliştiği iddiasıyla açılan davalarla da karşılaşmak mümkündür.

Anayasa, idarenin kendi eylem ve işlemlerinden doğan zararları ödemekle yükümlü olduğunu hüküm altına almıştır. ${ }^{[1]}$

Iddarenin yürütmekle yükümlü olduğu bir hizmetin kuruluşunda, düzenlenişinde veya işleyişindeki nesnel nitelikli bozukluk, aksaklık veya boşluk olarak

- İletişim adresi: Dr. Serdar Şirazi, Florya Plaza, Şenlikköy Mah., Eski Halkalı Cad., No: 3, K: 2, D: 25 B. Florya, Bakırköy, İstanbul Tel: 0536 - 6811187 e-posta: drserdarsirazi@yahoo.com

- Geliș tarihi: 3 Ekim $2020 \quad$ Kabul tarihi: 10 Ekim 2020 
tanımlanabilen hizmet kusuru; hizmetin kötü işlemesi, geç işlemesi veya hiç işlememesi hallerinde gerçekleşmekte ve idarenin tazmin yükümlülüğünün doğmasına yol açmaktadır.

İdarenin yürütmekle yükümlü olduğu bir hizmet olarak da sağlık hizmeti ön safhalarda yer almaktadır.

İdare hukuku ilkeleri ve yerleşik yargı içtihatlarına göre, zarar gören kişinin hizmetten yararlanan durumunda olduğu ve hizmetin riskli bir nitelik taşıdığı hallerde, idarenin tazmin yükümlülügünün doğması için zararın, idarenin ağır hizmet kusuru sonucu meydana gelmiş olması gerekmektedir.

Dolayısıyla bünyesinde risk taşıyan hizmetlerden olan sağlık hizmetinden yararlanan kişinin zarara uğraması halinde, bu zararın idare tarafindan tazmini, idarenin ağır hizmet kusurunun varlığı halinde mümkün olabilir.

Bununla birlikte hekim-hasta ilişkisi hukuki açıdan sıklıkla vekâlet sözleşmesi kapsamında değerlendirilmekte ve hekimin yani vekilin hafif kusurundan dahi sorumlu olduğuna dair yargı kararlarına oldukça sık rastlanmaktadır.

\section{ÖRNEK DAVALAR}

\section{Örnek Dava 1: Fasiyal Paralizi Nedeniyle Kortizon Uygulanan Hastada Gelişen İki Taraflı Femur Başı AVN'si}

Danıştay 15. Dairesi tarafindan karar verilen ${ }^{[2]}$ ve fasyal paralizi nedeniyle nöroloji uzmanı tarafından steroid tedavisi uygulanan bir hastanın uğradığı zarara karşılık tazminat talebiyle açılan bir dava idari olarak ilk örnek dava olarak ele alınacaktır.

Davacıya, 21.03.2006 tarihinde geçirdiği fasiyal paralizi nedeniyle nöroloji uzmanı tarafından steroid tedavisi verilmiş ve tedavinin 5 . ayında ağrıları nedeniyle hastaneye başvurmuş. Hastane kayıtlarında tanı olarak miyalji ve bel ağrısı kodları girilmiş. Hastanın kayıtları incelendiğinde; bel ağrısına yönelik tetkiklerin yapıldığı, kalçaya yönelik ise hiçbir tetkikin yapılmadığı gözlenmiştir.

Ekstremitede gelişen kısalık ve kalça hareket kısıtIılığı sonucu yapılan tetkiklerde, kalçada (femur başında) avasküler nekroz tespit edilmesi üzerine davacı meydana gelen zararına istinaden idareye karşı sağlık hizmetinin kusurlu sunulduğu gerekçesiyle başvurmuş. Idarenin yapılan başvuruyu reddetmesi sonucunda da dava açılmış. Dosya Cumhuriyet Savcısı'nın yaptı̆̆ı soruşturma kapsamında bilirkişi incelemesi için Adli Tıp 3. İhtisas Kurulu'na gönderilmiş. Adli Tıp Kurumu dosyaya üniversite hastanesinden alınan bilimsel mütalaa ile birlikte değerlendirmiş. Romatoloji Bilim Dalı tarafından verilen rapora göre steroid tedavisinin 1. ayında dahi osteonekroza neden olabileceği bilgisi sunulmuş. Fizik Tedavi ve Rehabilitasyon Anabilim Dalı tarafından verilen görüşte de yaşanan avasküler nekrozun kortizon kullanımına bağlı ortaya çıkan nadir yan etkilerden olduğu bilgisi verilmiş. Adli Tıp Kurumu'nun ilgili kurulu da verdiği raporda hastanın bel ağrısı nedeniyle poliklinik değerlendirilmesinde mekanik bel ağrısı tanısıyla tedavi verilmiş olduğu ancak kalça avasküler nekroz tanısının konulmamış olmasının eksiklik olduğunu ancak avasküler nekroz açısından baş sorumluluğun hekime atfedilmesinin hakkaniyetli olmayacağı bildirilmiş ve hekime $1 / 16$ oranında kusur atfedilmiş.

İdare ve ilgili hekimler yaptığı savunmada: 02.11.2006 tarihinde lomber manyetik rezonans (MR) tetkiki yapıldığını ve normal sınırlarda geldiğini, mekanik bel ağrısı düşünülerek tedavi verildiğini, 31.08.2007 tarihinde çekilen MR sonucunda iki taraflı (bilateral) kalça evre 3-4 avasküler nekrozu tanısının konulduğunu; ortopedi ve travmatoloji uzmanı tarafından verilen ifadede de kişinin kalça ağrısı şikayetinin olmadığı ve bu yüzden kalça eklemine yönelik tetkik yapılmadığı belirtilmiş.

Yerel mahkeme de Adli Tıp Kurumu'nun raporuna istinaden davanın reddine karar vermiş ancak karar davacı tarafindan temyiz edilmiş.

Danıştay'ın verdiği nihai kararda Adli Tıp Kurumu raporunda davacıda gelişen durumun kortizon uygulamasının komplikasyonu olarak kabul edilmiş. İdari eylemle zarar arasında nedensellik bağının kurulamadığından dolayı maddi tazminata hükmedilmesinin koşullarının oluşmadığını, kortizon tedavisini veren hekimin hastaya bu komplikasyonlar konusunda yeterli bilgilendirme yapması gerektiğini, ayrıca aylık takiplerle hastanın kontrol altında tutulması gerektiği, ağrı nedeniyle başvurduğu hekimin kalça avasküler nekroz tanısını koymamış olmasının yürütülen sağlık hizmetinin gerektiği gibi işletilmediği ve davacıda üzüntü ve endişe yaratacağından dolayı manevi tazminat talebinin değerlendirilmesi gerektiği kanaatine varmış.

Danıştay sağlık hizmetlerinin bünyesinde risk taşıyan tıbbi ve teknik bilgiyi gerektiren hizmetlerden olduğu, sağlık hizmetinden yararlanan bir kişinin zarara uğraması halinde zararın doğmasında idarenin hizmet kusurunun bulunup bulunmadığı da ancak konusunda uzman olan kişi ya da kuruluşlarca yapılacak detaylı incelemeler sonucunda ortaya konabileceğini de ayrıca belirtmiştir.

Danıştay'ın yaygın görüşüne göre; manevi tazminat, manevi zararın varlığında sadece şeref, haysiyet ve onur kırıcı işlem ve eylemlere ya da kişilerin vücut bütünlügünde meydana gelen sakatlık haline, ölüm nedeniyle ağır bir elem, üzüntü duyulması şartına bağlı olmadığı, 
idarenin yürütmekte olduğu kamu hizmetinin gereği gibi eksiksiz olarak sunamaması nedeniyle ilgililerin yeterli hizmet alamamalarından dolayı üzüntü ve sıkıntı duymaları manevi zararın varlığı ve manevi tazminatın hükmedilmesi için yeterli olarak kabul edilmektedir. Bu şekilde Danıştay idare Mahkemesi'nin vermiş olduğu kararı bozmuş ve daha detaylı bilirkişi incelemesi yapılmak üzere davacının temyiz istemini kabul ederek davayı yerel mahkemeye geri göndermiştir.

Sağlık hizmeti devlet hastanesi, üniversite hastanesi veya özel hastanelerde sunulduğuna bakılmaksızın bir kamu hizmeti olarak görülmektedir. Burada idarenin eksiksiz hizmet sunması gerektiği ve bu hizmetin sunulamaması nedeniyle kişinin üzüntü ve sıkıntı duyması sonucunda manevi tazminata hükmedilebileceği görüşü üzerinde durulması gereken bir konu olarak karşımızda durmaktadır. Söz konusu davada da bunun üzerinde durulmuş ve manevi tazminat hükmedilmesi gerektiği vurgulanmıştır.

Tedaviye başlayacak hekimin tedavinin kapsamı, riskleri, tedavinin süreci ve takip aralıklarını hastaya bildirmesi ve bu konuda özenli olmakla birlikte bel ağrısı ile poliklinikte hastayı değerlendiren hekimlerin de anamnezde steroid kullanım öyküsünü almaları halinde kalça avasküler nekroz ayırıcı tanısını düşünüp buna yönelik muayene ve tetkik isteme şeklinde değerlendirmede bulunması dikkat ve özen yükümlülügüüün gereklerindendir.

\section{Örnek Dava 2: Femur Boyun Kırı̆̆ı Ameliyatı Sonrası Gelişen AVN}

Danıştay'ın bir başka kararında ${ }^{[3]}$; kırk beş yaşındaki davacı ağaçtan düşme sonrası devlet hastanesine kaldırılmış, kalça ve el bileğinde kırıklar tespit edilerek el bileği kırığı konservatif olarak tedavi edilmiş. Femur boyun kırığına ise Smith Peterson plak vida sistemiyle tespit uygulanmış. Hasta tedavi sonrası $\% 40$ oranında sakat kalması neticesinde tedavisinin hatalı yapıldığı iddiasıyla dava açmış.

Hastanın ameliyatından sonra femur başında avasküler nekroz gelişmiş ve bilirkişi incelemesinde hastaya parsiyel protez uygulanmasının daha uygun olacağı, ileri yaşlarda bölgenin damarsal yapısı itibariyle kaynamanın mümkün görülmediği belirtilerek tedaviyi gerçekleştiren hekime kusur atfedilmiş. Davalı idare ve müdahil hekim tarafindan karar düzeltme aşamasında dosyaya Adli Tıp ihtisas Kurulu'nun raporu sunulmuş ve raporda Türk Ortopedi ve Travmatoloji Birliği (TOTBiD) Sağlık Hukuku Kurulundan (SHK) alınan bilimsel görüş incelemesi de yer almış. TOTBID - SHK'nin vermiş olduğu bilimsel mütalaada 45 yaşında femur boyun kırığı olgularında parsiyel protez uygulanması gerektiği şeklinde görüşün kesinlikle doğru olmadığı, şahısta gelişen avasküler nekrozun istenmeyen bir komplikasyon olduğu ifade edilmiş. TOTBID SHK'nin bilimsel mütalaasına istinaden Adli Tıp ìtisas Kurulu müdahaleyi yapan hekime kusur atfetmemiş. Birbiri ile çelişen iki ayrı bilirkişi raporu olmasından dolayı da Danıştay dosyanın Adli Tıp Kurumu Genel Kurulu'na gönderilerek söz konusu çelişkinin giderilmesine ve ilgili kısmın bozulmasına karar vermiştir.

Danıştay söz konusu davada davacıya tedavide parsiyel protez uygulanmasının gerekli olup olmadığının ve davacıya uygulanan tedavide idarenin hizmet kusurunun bulunup bulunmadığına dair birbirinden farklılık arz eden bilirkişi raporları arasındaki çelişkiyi gidermek amacıyla Adli Tıp Genel Kurulu'ndan rapor alınarak hükme bağlanmasının uygun olduğu kanaatine varmıştır.

Söz konusu davada yapılan ilk bilirkişi incelemesinin bilimselliğinin üzerinde durulması gerekmekte ve yazılan uygun olmayan rapora istinaden mahkemenin verdiği kararın nasıl değişebileceği açıkça gözler önüne serilmektedir. Ancak TOTBID - SHK'nin vermiş olduğu bilimsel görüş davanın seyrini değiştirmiş olmakla birlikte ilk verilen bilirkişi raporunun olumsuz etkisi Danıştay tarafından göz önünde bulundurularak çelişki olarak kabul edilmiş ve çelişkinin giderilmesi için Genel Kurul kararı alınması gerektiğine karar vermiştir.

Bununla birlikte ameliyat için kullanılacak geçici ve/ veya kalıcı implant kullanımında güncel tıbba uygun implant seçiminde bulunulması, ileride atfedilecek bilimsel olmayan ve olumsuzluk içeren ithamlara karşı bilimsel mütalaa sunularak aşılabilmesine imkân sağlayacaktır. Femur boyun kırı̆gı nedeniyle plak-vida ile veya benzeri yöntemlerle tespit uygulanan özellikle genç hastalara; bölgenin anatomik özellikleri nedeniyle kırığın kaynamayabileceği, kırık zemininde zamanla avasküler nekroz gelişebileceği ve ileride protez dahil ikincil ameliyatların gerekebileceği bilgisi verilerek yazılı olarak kayıt altına alınması gerekmektedir.

\section{Örnek Dava 3: El Bileği Perilunat Kırıklı Çıkığı Sonrası Oluşan Lunatumda ON ve Kaynamama}

Bir diğer vakada ${ }^{[4]}$ motosiklet kazası sonucu sağ el bilek perilunat kırıklı çıkık tanısı ile yaralanmadan bir hafta sonra ameliyat olan hasta ameliyat sonrası dönemde el bileğinde kanamanın olduğunu, daha sonra kanamanın devam etmesi sonucu takılan Kirschner (K) tellerinden ikisinin geri çekildiğini, 8 hafta sonra kanamanın devam ettiğini ve kırıkta kaynamama olduğunu, 2 ay sonra başka merkezde ameliyat olduğunu, tüm bunların neticesinde hatalı tıbbi müdahale yapıldığını ve el bileğinde hareket kısıtlılığı kaldığını iddia ederek dava açmış. 
Adli Tıp 3. İhtisas Kurulu tarafından yapılan değerlendirme sonucunda davacının tedavisinin uygun olduğuna, gelişen lunatum nekrozunun ve kaynamamanın komplikasyon olduğuna, dolayısıyla hekimin kusurunun olmadığına kanaat getirmiş.

Yerel mahkeme Adli Tıp'ın kararına istinaden davanın reddine karar vermiş ve karar davacı tarafından temyiz edilmiş.

Davacı ameliyatı gerçekleştiren doktorun eski yöntemle ameliyat yaptığını ve bunun hatalı bir tedavi olduğunu, Herbert vidası kullanılması gerektiğini, bunun yerine tel kullanılarak oluşan kemikteki kanamanın bası yolu ile durdurulmuş olmasının kaynamama ve avasküler nekroz şeklinde komplikasyonun oluşumuna katkıda bulunduğunu iddia etmiş.

Yargıtay'ın ilgili dairesi de epikrizde bulunan ve radyal arter yaralanmasının uç uca onarım yapıldığı bilgisine Adli Tıp Kurumu'nun değinmediğini ve bu konuda detaylı bir bilirkişi raporu alınması gerektiği gerekçesiyle davacının temyiz başvurusunu kabul ederek kararı bozmuş.

Burada davacının muhtemel bir bilimsel mütalaa yazısı ile temyiz başvurusunda bulunduğu, bilimsel mütalaada K-telleri ile yapılan ameliyatın yanlış bir seçim olduğu, bunun yerine Herbert vidası ile yapılması gerektiğine dair bir rapor alınmış olduğu düşünülmektedir. Bu kadar spesifik bir konunun davacı veya avukatı tarafından bilinmesi hayatın olağan akışına aykırıdır. Ancak yazıldığı düşünülen bu mütalaanın da bilimselliği tartışma konusu olarak değerlendirilmesi gereken önemli bir husustur.

Yargıtay içtihatlarına göre hasta hekim ilişkisi vekâlet sözleşmesine dayanmakta ve vekil, yani hekim iş görürken yöneldiği sonucun elde edilmemesinden değil, bu sonuca ulaşmak için yaptığı uğraşların özenle görülmemesinden sorumlu olarak kabul edilmektedir. Vekilin sorumluluğu, genel olarak işçinin sorumluluğuna ilişkin kurallara bağlıdır. ${ }^{[5]}$

Vekil, işçi gibi özenle davranmak zorunda olup, hafif kusurundan bile sorumludur. ${ }^{[6]}$ Yani hekimin meslek alanı içinde olan bütün kusurlarının (ki buna hafif kusurlar da dâhil) sorumluluğu kapsamında olduğu kabul edilmektedir. Hekimin hastanın zarar görmemesi için yalnız mesleki değil, genel hayat tecrübelerine göre herkese yüklenebilecek dikkat ve özeni göstermek zorunda olduğu kabul edilmektedir. Ayrıca hekime güvenen hastanın titiz bir ihtimam ve dikkat gösterme beklentisinde haklı olduğuna dair vurgu verilen kararlar da mükerrer olarak karşımıza çıkmaktadır. Özen göstermeyen vekil yani hekim vekâleti gereği gibi ifa etmemiş sayılmaktadır ve bunun hukukta tazminat olarak yansıması bulunmaktadır.

\section{Örnek Dava 4: Talusta İskemik Nekrozu Olan Hastaya Allogreft ile Pantalar Artrodez Uygulanması}

İstanbul 2. İdare Mahkemesinin ${ }^{[7]}$ verdiği bir diğer karar incelendiğinde; davacının sağ ayak bilek ağrısı nedeniyle ortopedi ve travmatoloji polikliniğine başvurduğu, yapılan tetkikler sonucunda talusta iskemik nekroz, ayrıca tibiotalar, subtalar ve talonaviküler eklemlerde artroz tespit edilerek allogreft kullanılarak pantalar artrodez ameliyatı yapıldığı, Adli Tıp Kurumu raporunda kişiye konulan tanının ve yapılan tedavi seçeneğinin doğru olduğu, ancak kullanılan allogreft uygulamasının doğru olmadığı ve bu yönden ortopedi ve travmatoloji uzmanının kusurlu olduğu, fakat operasyonda elde edilmek istenen sonuç olan artrodezin davacıda elde edildiğinin saptandığı rapor edilmiş. Verilen bu rapora istinaden mahkeme ilgili idarenin vermiş olduğu hizmette kusur olduğunu kanaat getirerek idarenin tazminat ödemesine karar vermiş.

Pantalar artrodez operasyonlarından sonra kaynamama istenmeyen fakat gerçekleşebilecek bir durumdur. Ancak kaynamamanın komplikasyon olarak nitelendirilebilmesi için hastaya uygulanan tanı, tedavi ve takip uygulamalarının doğru şekilde yapılması ve gelişebilecek olumsuzluklara karşı hastayı önceden bilgilendirilip rızasının alınmış olması gerekmektedir. Böyle bir durumda kaynamama (nonunion) komplikasyon olarak kabul edilebilecekken, tanı tedavi ve takiplerde uygunsuzluk malpraktis olarak değerlendirilebilecektir. Dolayısıyla vekil (hekim) vekâlet görevinde bulunurken dikkat ve özen yükümlülüğünü yerine getirmemiş olmakta ve oluşan zararı tazmin etmek durumunda kalabilmektedir.

Danıştay somut davada manevi tazminatı onayarak maddi tazminat açısından detaylı incelenmek üzere tekrar yerel mahkemeye geri göndermiş.

Söz konusu davada artrodez operasyonunda kaynamama değil allogreft kullanılmasının bir kusur olduğu belirtilmiş. Yani tedavi uygulamasında kusur görülmüş ve mahkeme bu kusura karşıılık manevi tazminata hükmetmiş. Hekim tedavi seçiminde güncel tıbbi bilgiler çerçevesinde serbest olmakla birlikte yaptığı tedavi seçimini bilimsel olarak ortaya koyabilmelidir. Söz konusu davada allogreft kullanma gerekçeleri ve otogreft kullanmama nedenleri hasta kayıtlarında da yer verilerek ileride gelişebilecek uyuşmazlıkların çözümünde ortaya konulabilecek önemli veri (done) olarak gündeme gelebilecektir.

\section{Örnek Dava 5: Tanı Konulmamış Femur Boynu Kırığı Sonrası Oluşan Avasküler Nekroz Olgusu}

Diğer bir örnek de Askeri Yargıtay ${ }^{[8]}$ tarafından verilmiş bir karar ile ilgilidir. Yere düşürülme sonucu kalça travması geçiren ve daha sonra hareket kısıtlılığı gelişen 
şahsın yargılama sırasında, yaralanmanın, basit tıbbi müdahale ile giderilemeyeceğine, vücutta saptanan kemik kırığının, hayat fonksiyonlarını, ağır derecede etkileyecek nitelikte olduğuna, sağ bacakta $3 \mathrm{~cm}$ 'lik kısalık ve sağ kalça eklem hareketinin $20^{\circ}$ limitli olmasından dolayı, organlarından birinin sağ bacağının işlevinin, sürekli zayıflamasına neden olduğuna ilişkin kati rapor tanzim edildiği tespit edilmiş ve bu suretle sanığın (yere düşüren kişinin) mahkûmiyetine karar verilmiş. Sanı̆̆ın; meydana gelen sakatlığın oluşmasının, sanığın eylemi sonucu değil, "teşhis ve tedavisinin hatalı ve gecikerek yapılması sonucu meydana gelmiştir" şeklindeki itirazı üzerine Askeri Yargıtay kararı, iddiaların karşılanmadığı gerekçesiyle bozmuştur.

Söz konusu davada elde edilen bilgilere göre femur boyun kırığı olduğu, bunun atlanmış olduğu, kaynamama ve femur başı avasküler nekrozu gelişerek sakatlığın olduğu düşünülebilecektir.

Burada göz önünde bulundurulması gereken durum ceza hukuku açısından sanığın eylemi ile (askeri yere düşürme) meydana gelen zarar (kalça avasküler nekrozu) arasında illiyet bağı olmadığı iddiasının Askeri Yargıtay tarafindan kabul edilip Askeri Mahkemenin verdiği kararı bozması. Dolayısıyla meydana gelen zarardan tedaviyi yapan veya tanıyı atlayan hekimin sorumlu olduğu iddiası üzerine dava ilerleyecek ve Askeri Mahkeme bir karar verecektir.
Travma nedeniyle başvuran hastanın yapılacak detaylı muayenesinde şüphe duyulması halinde ileri görüntüleme tekniklerinin istenmesi ileride yaşanabilecek gerek tıbbi gerek hukuki olumsuzluklara karşı koruyucu olacaktır. Söz konusu vakada femur boyun kırığı olduğu ve bunun radyografi ile tespit edilememesine bağlı olarak avasküler nekroz geliştiği düşünüldüğünde, ayrıca bazı femur boyun kırıklarının radyografi (düz grafi) ile tespit edilmesinde yaşanan güçlükler göz önünde bulundurulduğunda kalça travması nedeniyle başvuran hastalarda ileri görüntüleme tetkiklerinden çok da geri kalmamak gerektiği kanaati oluşmaktadır.

\section{KAYNAKLAR}

1. T.C. Anayasası m.125.

2. Danıştay 15. Daire E: 2014/84 K: 2018/5698 K.T. 06.06.2018.

3. Danıştay 15. Daire E: 2014/9309 K: 2015/6400 K.T. 22.10.2015.

4. Yargitay 13. Hukuk Dairesi E: 2014/26571 K: 2015/33584 K.T. 18.11.2015.

5. Borçlar Kanunun m.390 (eski) - Türk Borçlar Kanunu m.506 (yeni).

6. Borçlar Kanunun m.321.

7. Danıştay 15. Daire E: 2015/4695 K: 2016/585 K.T. 04.02.2016.

8. Askeri Yargıtay 4. Daire E: 2017/151 K: 2017/168 K.T. 07.04.2017. 